\section{Pedro e seus circuitos na cidade de São Paulo:} religiosidade e situação de rua *
Debora Galvani ${ }^{1}$
Denise Dias Barros ${ }^{2}$

GALVANI, D.; BARROS, D.D. Pedro's circuits in the city of São Paulo: religiosity and homelessness. Interface - Comunic., Saude, Educ., v.14, n.35, p.767-79, out./dez. 2010.
This is a case study based on the reconstitution of the life history of a homeless adult in the city of São Paulo. were the strategies in a 12-month long data collection. The analysis tried to reveal, in the process of identity construction, singularities able to resignify and grant historicity to the homelessness experience. To discuss Pedro's path, religiosity analysis is a crucial element for re-assessing his homelessness history. Allied to other nets, religiosity showed different possibilities of constructing interdependence nets, thus characterizing re-signification and sense reconstruction movements, and eluding disaffiliation processes so frequent in the case of people that experience rupture conducting to homelessness. In those processes, the socially negative identity linked to homelessness can be dislodged and widened, acquiring more elucidative delineations and dynamics. Nonetheless, there is always the need and the challenge of constructing collective alternatives to the precarious homelessness experience.

Keywords: Life history. Disaffiliation. Social nets. Homeless adults. Cultural antropology. Ethnographic research and life history
Trata-se de estudo de caso, com base na reconstituição da história de vida de um adulto em situação de rua na cidade de São Paulo. A pesquisa etnográfica e a história de vida compuseram as estratégias para coleta de dados, realizada durante 12 meses. Na análise, buscou-se desvendar singularidades no processo de construção de identidades capazes de redimensionar e conferir historicidade à experiência da situação de rua. $\mathrm{Na}$ discussão da trajetória de Pedro, a análise da religiosidade é fundamental para releitura da sua história de rua. Aliada a outras redes, mostrou possibilidades distintas de construção de redes de interdependência, caracterizando movimentos de ressignificação e de reconstrução de sentidos, afastando-se dos processos de desfiliação. A identidade socialmente negativa vinculada à situação de rua pode ser descentrada, adquirindo contornos e dinâmicas mais elucidativos. No entanto, ocorrem a necessidade e o desafio de construção de alternativas coletivas à precariedade da experiência de rua.

Palavras-chave: História de vida.

Desfiliação. Redes sociais. Adultos em situação de rua. Antropologia cultural.

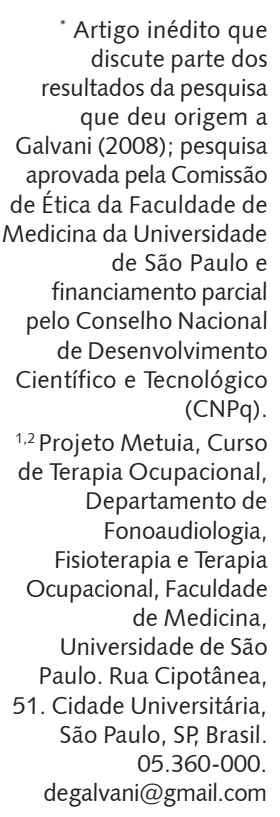
ute parte dos ultados da pesquisa Galvani (2008); pesquisa aprovada pela Comissão de Ética da Faculdade de edicina da Universidade financiamento parcial pelo Conselho Nacional de Desenvolvimento Científico e Tecnológico (CNPq).

1,2 Projeto Metuia, Curso Departamento de Fonoaudiologia,

Fisioterapia e Terapia de Medicina,
de (niversidade de Săo 1. Cidade Universitária, 05.360-000. degalvani@gmail.com 


\section{Introdução}

Com base na reconstituição de uma história de vida, apresentamos estudo de caso sobre a trajetória de um homem adulto que vive em situação de rua na cidade de São Paulo. O foco central recai sobre as estratégias singulares para criar e ampliar suas redes de suporte social, religioso, cultural, econômico e/ou afetivo a partir de situação em que o espaço das ruas é o articulador das relações sociais, da moradia e de trabalho. Trata-se de analisar a formação de grupos de pertencimento e de identidades coletivas, assim como as alternativas criadas para construir suportes e estabelecer novas possibilidades de vida.

Compreende-se que a população em situação de rua, enquanto grupo social (Oliven, 1995), transita entre zonas de vulnerabilidade e desfiliação, conforme definidas por Castel $(1998,1994)$, pois está frequentemente submetida à ausência de emprego ou a trabalhos temporários e a trajetórias marcadas por rupturas. Ressaltamos, entretanto, que

\section{[...] viver na rua não significa necessariamente viver sem dinheiro mas, sobretudo, significa adquirir o essencial para a sobrevivência sem passar pelo mercado. Não significa a eliminação de trabalho, mas o abandono do compromisso constante e cotidiano do emprego, substituído por outras formas de trabalho. Também não significa viver sozinho, mas estabelecer novos vínculos com diferentes pares. Assim, viver na rua é também transitar pela possibilidade de gerar renda como estratégia para agregar valor à própria existência. (Ghirardi et al., 2005, p.603)}

O que parece mais fecundo nos estudos de Castel $(1998,1994)$ para esta reflexão é o que se pode depreender do conceito de proteção próxima. Construída na esfera dos laços afetivos e familiares, nas redes de relações e na cultura, a proteção próxima cria campos de suporte e de partilha interpessoal mesmo na adversidade da precarização do trabalho. Para este autor, a proteção próxima é constituída pela tessitura de redes de sociabilidade e de solidariedade que encontra, na família e na dimensão da cultura, dois registros fundamentais. Constitui, assim, o húmus nutritivo para a camada mais miserável da população, onde se partilham bens e serviços e um sistema de trocas que mantém ou cria o laço social e o sentido. A desfiliação emerge quando as relações de proximidade (sistema de interdependência fundado em família, linhagem ou comunidade), que inscrevem uma pessoa em seu território na cumplicidade produzida pelo sentimento de pertencimento, tornam-se incapazes de garantir a reprodução da existência e assegurar a proteção.

Existe grande heterogeneidade de experiências entre pessoas que vivem em situação de rua (Galvani et al., 2006; Rosa, 2005). Ao longo de trabalho realizado desde 2001 no contexto do Projeto Metuia (Barros, Lopes, Galheigo, 2002), com adultos em situação de rua, e de pesquisa vinculada à dissertação de mestrado ${ }^{3}$, foram identificados grupos e pessoas que pareciam proporcionar referência para a discussão de formas endógenas/internas (e de auto-organização) de superação, ainda que parcial ou fugaz, da experiência negativa de desqualificação social e das sucessivas rupturas de laços sociais. Entre as histórias de vida trabalhadas durante a pesquisa, destaca-se, para este artigo, a análise do lugar da religiosidade e das redes de relações e de amizade na reconstrução do laço social e de pertencimento.

Pedro tem 43 anos de idade, é filho de baianos e nasceu em São Paulo (SP). Costuma vestir-se com uniforme de motorista de ônibus e contar histórias sobre
${ }^{3}$ Ver Galvani (2008). O Projeto Metuia é um núcleo interinstitucional de estudos, formação e ações pela cidadania de crianças, jovens e adultos em processo de ruptura das redes sociais de suporte vinculado ao Curso de Terapia Ocupacional da USP. 
${ }^{4}$ Expressão utilizada especialmente, por adultos em situação de rua, para nomear serviços e espaços de oferta de alimentação gratuita. sua vida, na perspectiva de que seus interlocutores aprendam com suas "cabeçadas", como diz, e com os ensinamentos religiosos que transmite quando tem oportunidade. Apresenta-se como ex-morador de rua e ex-mendigo que conseguiu, por meio da religiosidade aliada ao apoio da rede de serviços sociais e outras redes de trocas e de relações interpessoais, retornar ao convívio familiar e ao trabalho, mantendo-se abstinente do consumo de álcool e outras drogas.

$\mathrm{Na}$ discussão da trajetória de Pedro, a análise da religiosidade é elemento fundamental para a releitura da sua experiência de vida nas ruas de São Paulo. A participação na Igreja Adventista do Sétimo Dia (IASD), a inserção no trabalho como motorista de veículos pesados, o retorno ao convívio familiar, a participação na dinâmica da Praça da Sé, o recurso aos serviços da assistência social (como albergues, "bocas de rango" 4 e centros de serviços e de convivência) compuseram um conjunto de relações interpessoais para a reconstrução de sentimento de pertencimento, a ressignificação da experiência negativa e a reversão do processo de ruptura de redes e da deriva de sentidos.

Recorremos aos estudos de Magnani $(2003,2002,1996)$ sobre as cidades e as redes de pertencimento de grupos sociais urbanos. Ao articular a reflexão sobre a cidade e a etnografia, o pesquisador propõe - em contraposição ao que chamou de "olhar de fora e de longe" - o "olhar de perto e de dentro", que implica partir dos atores sociais,

[...] não como elementos isolados, dispersos e submetidos a uma inevitável massificação, mas que, por meio do uso vernacular da cidade (do espaço, dos equipamentos, das instituições) em esferas do trabalho, religiosidade, lazer, cultura, estratégias de sobrevivência, são os responsáveis por sua dinâmica cotidiana. (Magnani, 2002, p.18)

Assim, para compreender dinâmicas próprias às sociedades urbanas, este pesquisador criou o conceito de "pedaço", para explicar um tipo particular de relações sociais estabelecidas em um espaço que se transforma em ponto de referência para determinados grupos pertencentes a uma rede de relações, independente dos limites territoriais. Neste estudo, foi possível reconhecer os "pedaços" de pertencimento nas redes sociais de Pedro e, a partir destes, os trajetos (fluxos pela cidade) e os circuitos (rede de espaços e equipamentos referentes a determinada prática ou oferta de serviço).

Vale destacar que este estudo está situado na interface entre indivíduo e sociedade. Ao buscar uma superação da cisão entre indivíduo e sociedade, historicamente construída, Elias (1994) cunhou o conceito de interdependência entre os indivíduos. $\mathrm{O}$ autor mostrou que as ideias de indivíduo e de sociedade estão estreitamente articuladas por um processo interativo amplo; haveria uma relação de interdependência entre os indivíduos, como na imagem de uma rede de tecidos, que só pode ser compreendida em termos da maneira como os fios se ligam e de sua relação recíproca.

A interdependência pode ser expressa, assim, nas diferentes formas de pertencimento, como circuitos religiosos e artísticos, movimentos sociais e recomposições familiares, entre outros exemplos. A noção de construção de identidades proposta por Castells (2002, p.18) - que tem como base "a construção de significados a partir de atributos culturais ou ainda um conjunto de atributos inter-relacionados, o(s) qual(is) prevalece $(\mathrm{m})$ sobre outras fontes de significado" contribui para a análise do que pode ser a expressão prática da noção de interdependência. 
Compreendemos a população em situação de rua como grupo social composto por pessoas que utilizam os logradouros públicos como locais de habitação e para atividades cotidianas (dormir, alimentar-se e trabalhar), pernoitam em albergues por não disporem de moradia autônoma e fazem uso dos serviços da rede de assistência, como projetos de moradia provisória e centros de serviços (Varanda, 2003). A Fundação Instituto de Pesquisas Econômicas (Fipe) e a Secretaria da Assistência Social, desde 1991, realizaram pesquisas na cidade de São Paulo, buscando caracterizar esse grupo social. Os dados mais recentes (São Paulo, 2003) apontam para uma população de 10.394 pessoas em situação de rua, 6.184 em albergues e 4.208 morando na rua. No total, $84 \%$ são do sexo masculino, e a maior parte é de pessoas cuja origem é do estado de São Paulo.

\section{Metodologia}

A pesquisa etnográfica com foco nas histórias de vida compôs as estratégias de constituição das bases da discussão aqui apresentada (Víctora, Knauth, Hassen, 2000; Queiroz, 1988). Trata-se de pensar a etnografia em meio urbano e, desta forma, como sugeriram Magnani (2003, 2002, 1996) e Oliven (1995), aceitar o desafio ao pesquisador de interpretar sua própria cultura. Segundo Magnani (1996), nesse tipo de trabalho é preciso buscar a superação do sentimento de proximidade, criando certo distanciamento para transformar em estranho algo que parece familiar ao pesquisador.

No trabalho etnográfico, o pesquisador depara-se com a necessidade de produzir interpretações sobre grupos sociais ou trajetórias pessoais. Mas tais grupos e pessoas produzem igualmente interpretações sobre quem são e o que necessitam. Há, portanto, uma pluralidade de interpretações que devem ser consideradas, tanto durante a coleta de dados, como no processo de análise. Cabe lembrar que o confronto das interpretações é dificultado pelas distâncias entre pesquisador e pesquisado: diferenças de classe, gênero, idade, cultura e valores, entre outras. Como enfatizou Clifford (1998), os textos etnográficos são orquestrações de trocas polifônicas em situações politicamente carregadas. As subjetividades produzidas nessas trocas, frequentemente desiguais, fazem parte de um campo de construções de verdades. Assim, o termo "etno-grafia" pode ser traduzido por "escrita da cultura", como sugere Atkinson (1992).

Partimos da compreensão do reconhecimento do sujeito da pesquisa como interlocutor, pois, segundo Oliveira (2000), o trabalho etnográfico envolve o encontro com o "outro". Este "outro" é compreendido como interlocutor com quem se estabelece uma relação de cooperação, criando-se, desta maneira, a possibilidade de uma relação dialógica. Pelas razões expostas, adotamos, neste estudo, o termo "colaborador", como Meihy (2005), para enfatizar a necessidade de se construir uma relação de colaboração entre entrevistador e entrevistado.

A pesquisa de campo, realizada durante doze meses em 2006, desenvolveu-se por meio de entrevistas (com registro em áudio), observação de campo, visitas aos pedaços significativos sugeridos pelos colaboradores, pesquisa documental e bibliográfica. É preciso ressaltar, porém, que os primeiros contatos com a população adulta em situação de rua ocorreram em virtude de atividades de extensão universitária desenvolvidas pelo Projeto Metuia, em parceria com a Associação Minha Rua Minha Casa (AMRMC), iniciadas em 2001. Foi nesse contexto de convívio semanal que os estudos com foco em histórias de vida emergiram. A proposta de pesquisa - aprovada pela Comissão de Ética da Faculdade de Medicina da USP (protocolo 1209/05) - foi discutida com os usuários daquela associação e algumas pessoas foram convidadas a colaborar com o estudo. O convite aos colaboradores foi feito aos usuários que satisfizessem, pelo menos, dois dos seguintes requisitos: estar inserido em programa de moradia; participar de organização política (movimentos sociais específicos); integrar redes de relações de caráter religioso; integrar circuitos ligados a arte e cultura; utilizar serviços da rede assistencial como recurso complementar para organização de seu cotidiano; possuir formas de geração de renda. Além destas dimensões, que sugerem diferentes formas de participação social, foi critério de seleção o colaborador estar ou ter vivido em situação de rua por mais de dois anos.

O estudo foi realizado com cinco colaboradores, porém, aqui a discussão recai sobre a relação entre religiosidade e as redes de relações próximas na reconstrução do sentido e da participação social evidenciada pela história de Pedro. 
Ao iniciarmos o trabalho de campo, Pedro mantinha redes de relações de caráter religioso, além de ter construído formas de geração de renda e de utilizar a rede assistencial como recurso complementar para organização do cotidiano. Todas estas eram dimensões sinalizadoras do potencial de criação de laços sociais e de suporte interpessoal.

Vale destacar que, como parte do método, privilegiamos as escolhas do colaborador na definição do local de realização das entrevistas. Tais escolhas implicaram realizar entrevistas na Praça da Sé, por exemplo, e houve necessidade de lidar com as dificuldades que se impuseram em algumas situações, como interrupções e ruídos que prejudicaram a qualidade da gravação em áudio. Percebemos, por outro lado, que determinados locais eram muito significativos e pareciam capazes de potencializar as narrativas sobre experiências e vivências que neles se produziram, pois, naquele momento, já era possível observar que representavam "seus pedaços".

Foram realizadas, ainda, visitas dentro dos seus circuitos na cidade, atendendo às sugestões e aos convites do colaborador. Esse momento do estudo proporcionou informações da gestão do cotidiano e aproximação com coletivos diversos, como na Praça da Sé e na igreja. A casa da sua família e a AMRMC constam, igualmente, dos espaços de observação e interação com Pedro e sua rede de relações.

As entrevistas foram registradas, transcritas e, após a transcrição, textualizadas (Meihy, 2005). Neste processo de tradução do relato oral em texto escrito procurou-se manter a máxima fidelidade ao estilo do colaborador. As maneiras de falar revelam pertencimento grupal, a uma região, a uma faixa etária, entre outros aspectos; assim, os "erros" gramaticais foram mantidos em alguns casos.

A análise foi realizada com base na reconstituição da história de vida do colaborador, com o objetivo de mostrar suas redes de interdependência e de discutir sua singularidade no processo de construção de identidades capazes de redefinir sentidos, sentimentos de pertencimento e dar historicidade à experiência da situação de rua.

\section{De Capão Redondo à Praça da Sé}

Pedro é frequentador do centro de São Paulo, porém tem fortes laços na região do Capão Redondo. Morou com a família neste bairro da periferia paulistana até seus trinta anos. Parou de estudar aos 14 anos, após uma série de fracassos na escola, mas concluiu a $4^{a}$ série do Ensino Fundamental, quando começou a trabalhar como ajudante em feiras livres do seu bairro, pois precisava contribuir com a renda familiar. Aos 18 anos ingressou na atividade de carreteiro, realizando viagens pela cidade e outras regiões do Brasil. As constantes viagens favoreceram seu distanciamento da família, assim como as brigas frequentes entre seus pais, que acabaram optando pela separação. Pedro avaliou que o consumo de bebidas alcoólicas, presente desde sua adolescência, foi se tornando excessivo e passou a prejudicar seu desempenho no trabalho, suas relações familiares e com os amigos.

\footnotetext{
"Estou com 43 anos e faz mais ou menos dez anos que fui pra rua. Antes disso, sempre morei com a minha família. Morava com a minha família até que um dia minha mãe se separou do meu pai, e aí eu fiquei morando com meu pai, e ele me botou pra fora de casa. Eu já era velho, tinha uns 30 ou 33 anos quando ele me botou pra fora, porque eu bebia muito. [...] Aí, fui morar com a minha irmã. Aí, não chegou a fazer dez dias, me botou pra fora também. Aí fui morar na casa dum colega, que hoje é finado, aí o colega me botou pra fora também. Aí, vim conhecer aqui, a Praça da Sé. Descobri o que é albergue, morei, dormi nesses bancos da Praça, dormi debaixo dos viadutos. Albergue eu fui em todos!".
}

Sem renda e com dificuldade nas relações familiares, passou a dormir em hotéis de baixo custo. Não conseguiu novas oportunidades de trabalho e, quando seu dinheiro acabou, passou a dormir na rua: não havia a quem recorrer, todas as suas relações estavam muito desgastadas. Durante anos desligou-se da família.

Pedro considerou as transformações de sua relação com o trabalho como um dos fatores que motivou sua chegada à situação de rua. Avaliou que, cerca de 15 anos antes, era mais fácil encontrar trabalho em sua área e conseguia manter-se empregado, mesmo que necessitasse trocar de emprego frequentemente, pois não conseguia permanecer muito tempo no mesmo local de trabalho por 
consequência do abuso de bebidas alcoólicas. Esta trajetória mostra a confluência de dupla dinâmica de vulnerabilização da integração social: dissolução de vínculos e precarização ou ausência do trabalho, fatores que alimentam o processo de desfiliação.

Porém, vale destacar que, para Pedro, o fator desencadeador do seu processo de chegada à situação de rua foi o afastamento da prática religiosa.

"Eu nasci num lar cristão. Aí, na minha adolescência, eu desviei dos caminhos de Jesus, saí da igreja, comecei trabalhar no dia de sábado, comecei a trabalhar em feira de ajudante de pastel. Ali foi que eu comecei, que eu aprendi a beber bebida alcoólica. Comecei com um vinhozinho, aí quando eu fui abrir os olhos já tava na pinga. E, na idade de 18 anos, eu já bebia bastante pinga. E me tornei um motorista. Com 18 anos, já tirei a minha habilitação, na categoria D, na época só tirava categoria C. Aí eu comecei a beber, beber, mas me tornei um motorista profissional. Com 20 anos, eu saí da feira e fui trabalhar já como motorista profissional. Aí foi a minha trajetória: pegava emprego num dia e perdia no outro. Mas naquele tempo era fácil, né? Você perdia um emprego hoje e no outro dia já tava empregado!".

Seu destino foi o centro da cidade de São Paulo, mais especificamente a Praça da Sé, destino de muitos que "caem" na rua. Magnani (2003), ao estudar o lazer no centro de São Paulo, deparou-se com diferentes usos e apropriações do espaço urbano, os quais seriam significados ou ressignificados por práticas sociais.

Deslocamo-nos, então, para compreender algumas dessas práticas e a relação de Pedro com elas, circunscritas a determinado espaço, visível na geografia da cidade.

Pedro tornou-se um conhecedor deste espaço, e sua forma de utilizá-lo foi se transformando com o tempo. A dinâmica da praça é complexa; trataremos de descrevê-la a partir da perspectiva das relações estabelecidas por Pedro. Foi na praça que conheceu Maciel, artista de circo que realizava exibições e vendia produtos para a saúde. Trabalhou como seu auxiliar na segurança, venda dos produtos e coleta de doações, recebendo, para isso, uma contribuição financeira que variava de acordo com a arrecadação. Após alguns anos sem trabalhar, seu conhecimento sobre a praça, sua dinâmica e seus personagens, inclusive os policiais, renderam-lhe oportunidades de geração de renda.

Além da imponente catedral, marco da Igreja Católica, a praça concentra uma série de pregadores de diferentes orientações religiosas que ali coabitam (nem sempre pacificamente) e disputam a atenção dos transeuntes para divulgar seus conhecimentos e vender seus produtos. Os pregadores disputam, também, com os artistas que trabalham na rua. Chamam a atenção dos passantes e dos frequentadores da praça as grandes rodas em torno de um evento, que por si só atraem a curiosidade de outras pessoas. A praça também é espaço de trabalho de engraxates, cabeleireiro e vendedores da "feira do rolo" 5 , que se beneficiam do movimento para vender serviços ou produtos. Pudemos compreender que fazem parte da dinâmica da praça e que algumas pessoas, como Pedro, encontram conforto, entretenimento, serviços, amigos, ao vivenciar tal dinâmica. Há, portanto, pessoas que se utilizam da praça de maneira mais frequente, estão no seu pedaço. Com este grupo, Pedro vem se relacionando mais intensamente.

Uma das ações do proselitismo religioso que se estabelece na praça foi narrada por Pedro com muitos detalhes. A seguir, um trecho desta narrativa:

${ }^{5}$ Espaço informal de troca e venda de produtos usados. 
“E aquele negócio... A minha vida, eu estava cada vez mais andando que nem caranguejo: pra trás. Mentiras e mais mentiras, álcool e mais álcool, crack e mais crack, e por essa linha afora. Aí, até que num belo dum sábado... [...] Eu estava dormindo, quando de repente uma pessoa, uma voz meiga e suave, chegou no meu ouvido e falou: Jesus te ama! Aí deixou um folhetinho na minha mão. [...] Eu abri o folheto e estava escrito assim: vi novo céu e nova terra, vi a cidade santa descendo da parte de Deus, ataviada com seu noivo, adornada pra sua noiva. E o mal já não existirá e Deus enxugará de todas as suas lágrimas. E a morte já não existirá. Li assim, essas frases bonitas, e atrás estava escrito assim: Jesus te ama e Ele tem um plano na sua vida! Nossos queridos irmãos da Igreja Adventista do Sétimo Dia. Peguei aquele folhetinho, coloquei no bolso, aí tinha o carimbo da igreja, aqui na Rua Taguá, na Liberdade, próximo à estação do metrô Liberdade. Aí eu falei: vamos ver se essas igrejas de crente são boa mesmo?".

Foi desta maneira que Pedro descreveu seu retorno a IASD, com algumas idas e vindas, mas considerando esta abordagem na Praça da Sé como o momento que marcou o início do processo que chamou de "transformação". Diferentes redes e apoios, além das que foram estabelecidas na Sé e na IASD, foram citados neste percurso. Pretendemos, a seguir, reconstituir resumidamente esta trajetória.

\section{Espaços e redes na experiência de Pedro: assistência, trabalho e família}

Pedro ressaltou, em nossos encontros, que procurava mostrar sua "transformação de mendigo para trabalhador" e a influência da religião nessa passagem:

"No ano de 2001, aceitei Jesus como meu salvador, e aí o milagre foi operado na minha vida. Foi quando eu deixei o álcool e deixei de usar droga, que seria o crack".

Ao partir da ideia de "transformação" motivada pela "aceitação de Jesus", Pedro destacou a importância da recomposição de laços e das diferentes redes que considerou parte desse processo.

“Eu comecei aqui na Igreja Adventista da rua Taguá. [no centro da cidade], depois que eu fui pra Igreja do Capão Redondo [zona sul] e aí foi aonde eu conheci a Associação Minha Rua Minha Casa. Fui pra Associação, comecei ir nas bocas de rango, aí comecei dormir nos albergues, porque aí eu não estava bebendo mais, nem usando droga, aí os albergues estavam me acolhendo, eu estava lá direitinho. E, com o decorrer dos dias, foi passando, eu fui me integrando lá na Associação, tiraram meus documentos, a Rosana [coordenadora da AMRMC] me ajudou a tirar meus documentos, e eu comecei a fazer bicos, comecei a entrar na Frente de Trabalho e aí comecei a fazer bico aqui na Praça da Sé, vender coisas, comecei a trabalhar com um artista de rua, o Maciel [...] e aí até que eu entrei numa cooperativa de transporte coletivo. Trabalhei um ano lá. Só que lá num consegui juntar dinheiro, porque lá era uma cooperativa vagabunda, os caras roubavam. Aí, agora, nesse finalzinho de ano, entrei numa cooperativa boa. [...] Hoje já me encontro na sociedade. Voltei para minha casa, estou morando com a minha mãe".

Os serviços de assistência compuseram uma rede de suporte importante. A relação de Pedro com a rede de serviços da assistência foi marcada pela presença em albergues. Ao refletir sobre a sua história, Pedro associou sua frequência em tais serviços à possibilidade de se abster do consumo de álcool e outras drogas. Por diversas vezes, ao falar de sua participação em albergues, utilizou a expressão "me botaram pra fora", mostrando as dificuldades que teve em permanecer nestas instituições. A rotatividade e o não acolhimento pela falta de adaptação às regras foram dois pontos que chamaram a atenção nas suas reflexões sobre estes serviços.

Durante o trabalho de campo, foi possível perceber que Pedro tinha um profundo conhecimento da rede de serviços da assistência e se movimentava dentro deste circuito de acordo com as possibilidades 
oferecidas e suas necessidades. Um exemplo disso foi seu conhecimento sobre as chamadas "bocas de rango", a qualidade das refeições e as regras necessárias para conseguir ser incluído nos serviços. Alguns destes serviços pertenciam à rede de equipamentos conveniados com a Prefeitura Municipal de São Paulo, por meio da Secretaria de Desenvolvimento e Assistência Social (SMADS), mas alguns espaços de distribuição de comida eram conhecidos por alguns, como o centro espírita na região da Mooca, que distribuía comida aos domingos. Há, na cidade, uma série de situações como esta e só quem faz parte deste circuito consegue se manter informado. Foi no interior das relações do circuito da assistência que Pedro soube do trabalho da AMRMC. Neste espaço guardava seus pertences, lavava suas roupas, tomava banho, fazia as refeições e participava de atividades socioeducativas e de geração de renda. A intensidade de sua participação no serviço e o tipo de atividade realizada atrelavam-se à inserção ou não no trabalho, às relações estabelecidas com seus familiares e à possibilidade de adequação às regras institucionais e de convivência com equipe e usuários, assim como à flexibilidade no acolhimento institucional.

Pedro referiu-se muito pouco à AMRMC em suas reflexões e, quando o fez, além de reconhecer o apoio para tirar documentação e para geração de renda, nas participações nas frentes de trabalho do governo, avaliou que frequentava o serviço "porque é melhor do que ficar em casa", sobretudo nos momentos em que esteve desempregado. Informou também que gostava de frequentar a AMRMC "para dar uma força para o pessoal", pois participava de atividades de manutenção da instituição. Mesmo em períodos que estava trabalhando e morando com a família, Pedro frequentava esporadicamente as atividades da AMRMC.

Interessante notar que, para não depender da família, Pedro preferiu ficar em albergues e frequentando a AMRMC nos períodos em que esteve desempregado. Porém, ressaltou que o controle sobre o consumo de álcool e outras drogas foi elemento decisivo para sua reaproximação com os familiares.
"Aí a família viu que eu não estava mais bebendo. Aí, meu irmão chamou pra morar com ele, meu irmão mais velho. Aí comecei a morar com ele e consegui um emprego na cooperativa [empresa de transporte coletivo]. Aí eu comecei a morar lá, trabalhava na cooperativa, aí, depois dum belo dia, depois de um tempo, minha cunhada começou a jogar muito na cara, aí eu saí fora. Não por causa dele, por causa dela! Aí voltei a morar em albergue. E aí até que eu comecei a ganhar uns troquinhos e aluguei um quarto pra mim lá perto da cooperativa. Aí fiquei desempregado, a cooperativa ficou fraca, me enrolaram. Aí eu fiquei desempregado e voltei pro albergue".

A presença na $A M R M C$, somada à participação na IASD, foi essencial para que se reorganizasse. Foi por intermédio da IASD que conseguiu o trabalho de motorista de ônibus em uma empresa cujo dono também era adventista. É importante destacar que estar trabalhando, frequentar a igreja e mostrar à família que estava "curado" foram elementos decisivos para o fortalecimento e manutenção da relação de Pedro com seus familiares.

Mesmo que Pedro avalie as dificuldades com o consumo de bebida alcoólica na permanência nas suas atividades de geração de renda, ao longo do tempo tem se sujeitado a relações precárias de trabalho, sem estabilidade e garantias. Isso pode ser compreendido dentro de um processo social mais amplo, que Castel (1998) analisou como nova questão social, quando refletiu sobre as dinâmicas da filiação social com base no trabalho, enfatizando, no entanto, a relevância do processo de degradação da sociedade salarial. Pedro viveu "na pele" essa transformação do mercado de trabalho.

Exceto nos eventos religiosos, Pedro vestia-se com uniforme de motorista de ônibus, mesmo quando estava desempregado ou em dias de descanso. Parece ser necessário para ele se afirmar neste universo profissional, e é desta forma que quer ser identificado.

Historicamente, o não trabalho, a preguiça e a vagabundagem sofreram restrições, mais ou menos violentas. Segundo Castel (1998, p.424), em determinado momento histórico, base para a constituição da "sociedade salarial", há nítida separação entre os que trabalham e os que não trabalham, e estes são alvo de regulações. Na constituição da sociedade salarial, o "vagabundo" 
torna-se novamente, durante um ou dois decênios, o contramodelo abominado que representou na sociedade pré-industrial: a figura da associabilidade que é necessário erradicar, porque destoa numa sociedade que volta a endurecer as regulações do trabalho. (Castel, 1998, p.424)

Parece que é desta imagem que Pedro procurou se desvincular. Existe, ainda, segundo as reflexões do autor, a noção de construção identitária através da condição de assalariado, compreendida, para além da retribuição do salário, como "a condição a partir da qual os indivíduos estão distribuídos no espaço social" (Castel, 1998, p.478). Compartilhamos a compreensão deste autor de que, em nossa sociedade, o trabalho confere identidade às pessoas.

\section{Religiosidade: a IASD e novas redes}

Ser membro da IASD e seguir seu conjunto de valores e práticas possibilita a Pedro pertencer a um grupo específico e compartilhar uma série de códigos, inclusive nas relações familiares. Durante o trabalho de campo, as intensas narrativas sobre a IASD motivaram a busca de informações sobre a religião e uma visita à igreja que frequenta.

A igreja do bairro paulistano onde reside é a referência da família, e, entre seus familiares, existem aqueles que ocupam posições importantes na estrutura daquela denominação religiosa. A região concentra quantidade expressiva de instituições adventistas. Além de algumas igrejas, é lá que se localiza o Centro Universitário Adventista de São Paulo, onde ocorrem diversos eventos ligados à religião. Assim, Pedro mantém-se dentro de um circuito ligado à prática da IASD: além de comparecer aos cultos e à Escola Sabatina, acompanha os eventos na universidade e outros acontecimentos da igreja.

Pedro propôs uma visita a sua igreja em um sábado - dia indiscutivelmente importante dentro das práticas adventistas e, por consequência, na organização de seu cotidiano -, que envolveu visita à Escola Sabatina e participação no culto. Por sugestão do próprio Pedro, ao final da programação, entrevistamos o pastor, para quem nos apresentou como alguém que o conhecia da época da Praça da Sé e tinha visto sua transformação. O pastor, por sua vez, explicou alguns dos postulados fundamentais da IASD e de que maneira acreditava que Pedro havia se reorganizado.

“[...] Ele era uma pessoa que era um alcoólatra, vivia nas ruas, era uma pessoa que não tinha uma norma a seguir, um princípio de vida e uma vez que ele conheceu os princípios da Bíblia, simplesmente aceitou e passou a seguir esses princípios que lhe foram ensinados. Só que nós acreditamos que, além do fato do ensino, além de receber as instruções da Bíblia, existe um fator, que nós acreditamos, que é um fator sobrenatural onde Deus entra, através do Espírito Santo, tocando na vida dessa pessoa, trabalhando na sua própria consciência para que ela possa se despertar para necessidade de uma mudança".

O pastor considerou, por um lado, o fator "sobrenatural", que, em outros momentos, Pedro nomeou de "milagre"; por outro, os princípios "éticos e morais" que foram ensinados. Vale buscar a compreensão de alguns desses princípios - que podem apoiar a leitura da situação de Pedro -, assim como uma breve contextualização histórica dessa religião.

Como evidenciou Capellari (2001, p.45), a IASD é considerada uma religião paralela à Reforma, formando, no interior do protestantismo, um grupo específico de denominações religiosas, as quais, "nascidas no século XIX nos EUA, postulam que suas doutrinas foram reveladas de um modo especial, pela ação divina, sendo as principais a Igreja Adventista, a Igreja Mórmon e das Testemunhas de Jeová."

Oliveira Filho (2004), ao discutir a formação histórica da IASD, recuperou a construção de seu universo simbólico. Nascidas no contexto dos movimentos messiânicos do século XIX originados nos EUA, comunidades adventistas acreditavam em uma data prevista para o retorno do Messias; esse episódio ficou conhecido como "o grande desapontamento". Um pequeno grupo permaneceu em busca de explicações para o evento e manteve a referência do Advento e, a partir das visões proféticas de Ellen White, os adeptos aglutinaram-se e foi orientada a formação do universo simbólico adventista. 
Segundo o endereço eletrônico oficial da IASD no Brasil (<http://www.adventista.org.br>, indicado pelo pastor entrevistado como fonte segura de informações), adventista é uma referência à "crença" no Advento, ou seja, à segunda vinda de Jesus à Terra. A narrativa do pastor contribui nesta compreensão:

\begin{abstract}
“Nós aceitamos a Jesus Cristo como nosso salvador e nos preocupamos em observar todos os dez mandamentos, e entre esses mandamentos da lei de Deus, que acreditamos ser uma aliança, está o mandamento do sábado como dia do Senhor. Por isso o nosso nome, "Igreja Adventista" - porque nós aguardamos o Advento de Jesus, a volta de Jesus - , e "do Sétimo Dia", porque nós guardamos o sábado como o dia do Senhor, como está registrado em Êxodo, capítulo 20, verso de 8 a 11".
\end{abstract}

Como ficou dito, o sábado, nessas condições, é dia muito especial para essa igreja. É quando acontece a Escola Sabatina, na qual participam todos os batizados e os membros da Escola, interessados e futuros adeptos ao batismo (Oliveira Filho, 2004). Na Escola Sabatina, os bancos da igreja são divididos em classes, e cada uma destas classes tem seu professor, responsável por conduzir o estudo do dia. Pedro conduziu-nos aos bancos da igreja que representavam sua classe de referência e nos apresentou como visita, categoria distinta dos membros e batizados, facilmente identificável pela forma de organização. A experiência deixou evidente o proselitismo e a forma de acolhimento da religião. Após algum tempo de permanência na igreja, recebemos diversos bilhetes com palavras de boas-vindas e convites para estudar a Bíblia.

A prática de "pregar o evangelho" a outras pessoas é compartilhada por Pedro, que assume, na igreja, papel importante como os outros membros. A importância de cada membro dentro da igreja, assim como a explicação sobre a noção de transformação dentro do universo simbólico adventista, está referida neste trecho da entrevista do pastor:

\footnotetext{
“Então o papel da igreja hoje é pregar o evangelho de Jesus Cristo, que nós cremos, é a única maneira de o ser humano encontrar a salvação eterna. Logicamente que qualquer outro tipo de grupo pode ajudar na recuperação de uma pessoa, acreditamos que isso pode acontecer. Mas nós acreditamos que Jesus Cristo, ele é suficiente, no salmo 23 ele menciona assim: "O senhor é meu pastor e nada me faltará." Então nós entendemos que Jesus Cristo, quando ele entra na vida de uma pessoa, a vida dessa pessoa, ela é transformada, e como o motivo de todos os problemas, até os problemas de saúde, têm o seu ponto de partida na mente, nós acreditamos que uma pessoa sadia mentalmente, transformada pelo poder do Espírito Santo, compreendendo os aspectos morais e éticos que são apresentados na Bílbia ela pode não só encontrar um caminho, uma cura, para a sua própria alma, para a sua mente, como também pode ajudar a outras pessoas também. [...] Todo tempo que nós temos nós devemos utilizar para nossa família, para nosso bem-estar, mas também para o progresso da obra de Deus aqui na terra. Para pregação do evangelho".
}

Se no circuito da rede assistencial Pedro recebia ajuda, um apoio, dentro da IASD passou ao estatuto de quem tem um conhecimento a ser transmitido para outras pessoas, de importância ímpar, porque significa, para ele e para o grupo que compartilha os mesmos códigos, a "única forma de salvação". A religiosidade vai dando sentido a uma série de práticas e também promove novos desafios, como o de se manter dentro dos padrões "éticos e morais" expostos pelo pastor. Conseguir negociar os sábados como dia de folga no trabalho é um exemplo. No caso de Pedro, a conciliação é possível, porque trabalha em empresa cujo proprietário é adventista. Há também o esforço de se manter sem consumir carne de porco, tarefa difícil, já que feijoada e bisteca são pratos regularmente servidos nos restaurantes em que gosta de comer na região da Sé e nos quais compartilha uma série de valores com outros frequentadores. Desta maneira, haverá sempre a necessidade de negociação, em vários sentidos, visto que se trata do encontro de diferentes práticas culturais dentro da mesma sociedade. Como sugere Bhabha (2001), pode tratar-se da construção de espaços de fronteira que permitam o diálogo e a negociação cultural. 
A experiência de vida nas ruas não é negada, nem por seus familiares nem pelos pastores. Ao contrário, pareceu adquirir novos sentidos na medida em que se transformou em testemunho de Pedro reforçado pela palavra pública dos pastores, os quais encontraram, em sua história, uma forma de renovar a eficácia simbólica (Lévi-Strauss, 1975) da sua igreja, evocando a transfomação pessoal do fiel e reforçando as práticas e os valores que aquele grupo compartilha.

Lembremos, ainda, que a relação entre religiosidade e processos de cura forma interessante interface para a análise desta trajetória. O tema é complexo. Sanchez e Nappo (2007) fizeram uma revisão da literatura científica (de trabalhos indexados nas bases de dados PubMed e Scielo entre 1976 e 2006) sobre a religiosidade e a espiritualidade como fatores de proteção do consumo de drogas e concluíram que

[...] a frequência constante a uma igreja, a prática dos conceitos propostos por uma religião e a importância dada à religião e à educação religiosa na infância são possíveis fatores protetores do consumo de drogas. Verifica-se também uma possível influência positiva da religiosidade para a recuperação dos dependentes de drogas. (Sanchez, Nappo, 2007, p.79)

Há, segundo as autoras, um campo aberto à investigação, pois quase todas as pesquisas encontradas são quantitativas, e a exploração do tema no contexto brasileiro poderia trazer novas contribuições à saúde pública, haja vista a forte influência das religiões em processos assistenciais.

\section{Apontamentos finais}

À medida que reconstituímos a história de vida de Pedro, seus circuitos e "pedaços" de pertencimento foram ficando aparentes e revelaram as diversas alternativas que conseguiu criar, mesmo em situações de vulnerabilidade. Ao compartilhar códigos e símbolos, nosso colaborador torna-se pertencente a determinados circuitos, que transcendem o da assistência e parecem contribuir para a construção e o fortalecimento de redes e de identidades interligadas e interdependentes. As diversas formas de participação social que observamos na trajetória de Pedro nos mostraram uma complexa rede e movimentos em busca de trocas em diferentes setores da sociedade. A participação nos serviços da rede assistencial, por exemplo, não se configurou como único recurso utilizado e não significou relação de dependência, situação comumente atribuída a seus usuários. A Igreja, as relações na Praça da Sé, a família e o trabalho compuseram diferentes possibilidades de trocas, colaborando para a construção da proteção próxima. Nesta trajetória, a religiosidade pareceu fornecer bases importantes para a construção de identidade coletiva e o pertencimento.

O estudo das redes sociais formadas pelas pessoas em permanente presença ou interação com a situação de rua pode ser enriquecido se a abordagem apreender, além das dimensões do trabalho e da moradia, as da religiosidade, da cultura, do lazer e da participação política (em movimentos sociais específicos). Há necessidade de se compreender, de forma aprofundada, a complexidade das dinâmicas de dissociação social e dos movimentos opostos a esta, para contribuir com a construção de práticas que buscam equacionar as dificuldades enfrentadas pelo grupo social em questão. Permanece o desafio e a necessidade de se produzirem, a partir de relações de interlocução, circunstâncias que evitem a chegada de pessoas à situação de rua, assim como se construírem alternativas coletivas.

\section{Colaboradores}

As autoras trabalharam juntas em todas as etapas de produção do manuscrito. 


\section{Referências}

ATKINSON, P. Understanding ethnographic texts. London: Sage Publications, 1992.

BARROS, D.D.; LOPES, R.E.; GALHEIGO, S.M. Projeto Metuia - terapia ocupacional no campo social. O Mundo da Saúde, v.26, n.3, p.365-9, 2002.

BHABHA, H. O local da cultura. Belo Horizonte: Ed. UFMG, 2001.

CAPELLARI, M.A. Sob o olhar da razão: as religiões não católicas e as ciências humanas no Brasil (1900-2000). 2001. Dissertação (Mestrado) - Faculdade de Filosofia, Letras e Ciências Humanas, Universidade de São Paulo, São Paulo. 2001.

CASTEL, R. Da indigência à exclusão, a desfiliação: precariedade do trabalho e vulnerabilidade relacional. In: LANCETTI, A. (Org.). Grupos e coletivos. São Paulo: Hucitec, 1994. p.21-48 (SaúdeLoucura 4).

Metamorfoses da questão social: uma crônica do salário. 5.ed. Petrópolis: Vozes, 1998.

CASTELLS, M. O poder da identidade. 3.ed. São Paulo: Paz e Terra, 2002 (A era da informação: economia, sociedade e cultura, v. II).

CLIFFORD, J. A experiência etnográfica: antropologia e literatura no século XX. Rio de Janeiro: Editora UFRJ, 1998.

ELIAS, N. A sociedade dos indivíduos. Rio de Janeiro: Jorge Zahar, 1994.

GALVANI, D. et al. Perfil dos frequentadores da casa de convivência e centro de serviços Associação Minha Rua Minha Casa entre 2002 e 2003. Rev. Ter. Ocup. USP, v.17, p.4856, 2006.

GALVANI, D. Itinerários e estratégias na construção de redes sociais e identidades de pessoas em situação de rua na cidade de São Paulo. 2008. Dissertação (Mestrado) Faculdade de Medicina, Universidade de São Paulo, São Paulo. 2008.

GHIRARDI, M.I.G. et al. Vida na rua e cooperativismo: transitando pela produção de valores. Interface - Comunic., Saude, Educ., v.9, n.8, p.601-10, 2005.

LÉVI-STRAUS, C. O feiticeiro e sua magia. In: Janeiro: Tempo Brasileiro, 1975. p.193-213.

Antropologia estrutural I. Rio de

MAGNANI, J.G.C. A rua e a evolução da sociabilidade. Os Urbanitas - Rev. Digital Antropol. Urbana, v.1, 2003. Disponível em: <http://www.osurbanitas.org/>. Acesso em: 7 jun. 2010.

De perto e de dentro: notas para uma etnografia urbana. Rev. Bras. Cienc.

Soc., v. 17, n.49, p.11-29, 2002. Disponível em: <http://www.scielo.br/scielo.php? script $=$ sci arttext\&pid $=S 0102-69092002000200002 \& \operatorname{lng}=e n \& n r m=i s o>$. Acesso em: 7 jun. 2010.

Quando o campo é a cidade: fazendo antropologia na metrópole. In:

MAGNANI, J.G.C.; TORRES, L. (Orgs.). Na metrópole: textos de antropologia urbana. São Paulo: Edusp/Fapesp, 1996. p.15-53.

MEIHY, J.C.S.B. Manual de história oral. 2.ed. São Paulo: Loyola, 2005.

OLIVEIRA, R.C. O trabalho do antropólogo: olhar, ouvir, escrever. In: trabalho do antropólogo. 2.ed. São Paulo: Edunesp, 2000. p.17-35. O

OLIVEIRA FILHO, J.J. Formação histórica do movimento adventista. Estud. Av., v.18, n.52, p.157-79, 2004. Disponível em: <http://www.scielo.br/pdf/ea/v18n52/ a12v1852.pdf>. Acesso em: 7 jun. 2010.

OLIVEN, G.R. A antropologia dos grupos urbanos. 5.ed. Petrópolis: Vozes, 1995. 
QUEIROZ, M.I.P. Relatos orais: do "indizível" ao "dizível". In: VON SIMSON, O.M. (Org.). Experimentos com histórias de vida (Itália-Brasil). São Paulo: Vértice, 1988. p.15-43.

ROSA, C.M.M. Vidas de rua. São Paulo: Hucitec/Associação Rede Rua, 2005.

SANCHEZ, Z.V.D.M.; NAPPO, S.A. A religiosidade, a espiritualidade e o consumo de drogas. Rev. Psiquiatr. Clin., v.34, n.1, p.73-81, 2007. Disponível em: <http:// www.scielo.br/scielo.php?script $=$ sci_arttext\&pid=S0101-60832007000700010 > . Acesso em: 7 jun. 2010

SÃO PAULO (Município). Secretaria de Assistência Social (SAS). Fundação Instituto de Pesquisas Econômicas (FIPE). Relatório final: estimativa do número de moradores de rua e estudo dos resultados obtidos com o SIS rua. São Paulo: SAS, 2003.

VARANDA, W. Do direito à vida à vida como direito. 2003. Dissertação (Mestrado) Faculdade de Saúde Pública, Universidade de São Paulo, São Paulo. 2003.

VÍCTORA, C.G.; KNAUTH, D.R.; HASSEN, M.N.A. Pesquisa qualitativa em saúde: uma introdução ao tema. Porto Alegre: Tomo Editorial, 2000.

GALVANI, D.; BARROS, D.D. Pedro y sus circuitos por la Ciudad de São Paulo, Brasil: religiosidad y situación de calle. Interface - Comunic., Saude, Educ., v.14, n.35, p.767-79, out./dez. 2010.

Se trata de estudio de caso con base en la reconstitución de la historia de vida de un adulto en situación de calle en la ciudad de São Paulo. La investigación etnográfica y la historia de vida han compuesto las estrategias para colecta de datos realizada durante 12 meses. En el análisis se busca exponer singularidades en el proceso de construcción de identidades capaces de obtener nueva dimensión y conferir historicidad a la experiencia de la situación de calle. En la discusión de la trayectoria de Pedro es fundamental el análisis de religiosidad para releer su historia de calle. Aliada a otras redes, muestra posibilidades distintas de construcción de redes de inter-dependencia, caracterizando movimientos de nuevos significados. La identidad socialmente negativa vinculada a la situación de calle se puede descentrar, adquiriendo contornos y dinámicas más elucidativos. Aún así se presenta la necesidad y el desafío de construcción de alternativas colectivas a la precariedad de la experiencia de calle.

Palabras clave: Historia de vida. Independencia. Redes sociales. Adultos en situación de calle. Antropología cultural.

Recebido em 19/05/09. Aprovado em 29/03/10 